respectively, a 3-h.p. synchronous-induction motor, a 3-h.p. three-phase Schrage type commutator motor, and a 5-h.p. commutator motor which can be operated in a number of ways both single and three-phase.

A number of transformers are also available for experimental work of various types, including an equipment which can be used for three- to twophase transformation.

\section{Oscillatory Discharges in a Magnetic Field}

$\mathrm{H}^{\mathrm{I}}$ IGH-FREQUENCY oscillations produced in electrical discharges under the influence of a magnetic field have attracted considerable attention in recent years. In addition to their purely physical interest, they have proved of value to the engineer in the magnetron oscillator, a device which is quite closely related to the cyclotron, or proton accelerator, of Lawrence and Livingston. The secondary emission electron-multiplier of P. T. Farnsworth provides another example of a device in which oscillations can be produced by means of the co-operation of electric and magnetic fields; it differs from the magnetron in that the two fields are aligned instead of being approximately perpendicular.

Prof. T. V. Ionescu has recently described (C.R., $202,1160$ and $1842 ; 203,57 ; 1936)$ some interesting results relating to a somewhat similar type of discharge tube having a thermionic cathode, two ring-shaped electron-accelerating electrodes and a circular plate which could be given a positive or negative potential with respect to the cathode. A magnetic field was directed along the common axis of these electrodes. (Some results obtained with a similar kind of discharge tube were reported by Prof. K. Okabe recently in NaTuRe, 138,685 ; 1936). Measurement of the voltage-current characteristics of the plate at a gas pressure of the order of $10^{-7} \mathrm{~mm}$. (reported by Prof. Ionescu and Mr. C. Mihul) showed that an electron current could reach that electrode when its potential was below cathode potential (presumably indicating the presence of electronic oscillations) without any magnetic field. The effect of the magnetic field was to increase this current and apparently to split it up into components having different velocities.

In further experiments at a pressure rather less than $10^{-4} \mathrm{~mm}$., a luminous column appeared along the axis of the tube, between the second accelerating electrode and the plate, at a definite value of magnetic field strength. The form of this column varied with the electrode potentials, the cathode emission, and the magnetic field strength, but it apparently did not show the nodes and loops characteristic of ordinary magnetic focusing. The luminous column was found to persist for an appreciable time after the cathode emission was stopped. Electron currents up to several times the cathode emission were observed to flow away from the plate (secondary emission) and regions of negative resistance were obtained.

The tube appeared to be generating powerful highfrequency oscillations, but the available power does not seem to have been determined; the frequencies were of the order of $100-1,000 \mathrm{mc} . / \mathrm{s}$. In the last paper a theory of the oscillations is given which treats them as plasma electron oscillations modified by the magnetic field; two oscillation frequencies then arise in a way reminiscent of the Zeeman effect.

\section{Educational Topics and Events}

Cambridge.-The General Board has recommended that Dr. U. R. Evans continues as assistant director of research in metallurgy for five years from January 1 , 1937 , or for so long as the Iron and Steel Industrial Research Council continues its grant to the University for scientific research on corrosion, whichever period be the shorter.

It is recommended by the General Board that a readership in plant physiology be established as from October 1, 1936, and that G. E. Briggs (St. John's College) be appointed to that post.

LeEds.-Mr. Frank Parkinson, head of the firm of Crompton Parkinson, Ltd., and an old student of the University, has given $£ 200,000$ for the proposed main frontage to the University in connexion with the reconstruction scheme now proceeding. Earlier this year, Mr. Parkinson gave $£ 50,000$ for the establishment of a scholarship fund.

SHEFFIELD.-The following appointments have recently been made: J. L. A. Grout, to be honorary lecturer in radiological anatomy: G. Clark, to be junior assistant bacteriologist; W. A. Timperley, to be research fellow in the Department of Physiology.

DR. H. S. Ruse, lecturer in mathematics in the University of Edinburgh, has been appointed professor of mathematics at University College, Southampton, in succession to Prof. R. C. J. Howland, who died in August last.

The British Film Institute's third annual report tells of much useful work done and in progress : of answering inquiries from all parts of the Empire; supervising production of thirteen films illustrative of physical training; helping to produce thirteen films for use in the teaching of physics, ecology, and history; publishing a catalogue of British medical films ; preparing for the Child Welfare Committee of the League of Nations a report on entertainment films for children, and organizing a conference for discussing the same subject; publishing a new leaflet on non-theatrical apparatus and films for schools; and maintaining the publication of the quarterly Sight and Sound and monthly film bulletins. Nine local branches were in operation in England and Ireland, and a Scottish Film Council represents the Institute in Scotland. All this is good so far as it goes, but it must be admitted that the growth in membership has been disappointing. On June 30 there were 597 full and 1,700 associate (branch) members. If any substantial progress is to be made towards realizing the Institute's object "to influence public opinion to appreciate the value of films as entertainment and instruction", its efforts will need to have much more vigorous and widespread backing than they have hitherto received. No local education authority in Great Britain could deny the enormous importance of the objects for which the Institute was formed, and every one of them might well be a full member and help towards the formation of a local branch; but in fact the total number of education committees in Great Britain which have joined is 36 . 